\title{
IoT-school guidance: A holistic approach to vocational self-awareness \& career path
}

\author{
Hicham EL MRABET ${ }^{1}$ (D) Abdelaziz AIT MOUSSA $^{1}$
}

Received: 27 January 2021 / Accepted: 13 April 2021 / Published online: 21 April 2021

(C) The Author(s), under exclusive licence to Springer Science+Business Media, LLC, part of Springer Nature 2021

\begin{abstract}
Schools are responsible for helping students in their vocational career development in the sense that they should sustain students in developing skills required by the job market. Pre-tertiary school guidance is an indispensable aspect, since poor scholar guidance is always associated with failure at school. In the context of career paths, we propose an innovative approach, a solution to guide pre-tertiary students to choose the optimum vocational path. The purpose of the current study is to develop a school guidance system called "IoT-School Guidance". The latter is supposed to create a smart and conducive environment for the successful adoption of school guidance using the Internet of things (IoT), given the fact that the IoT is the next revolutionary technology in the world where anything can transmit and receive information in real time. It is a new approach that includes implementing an adaptive orientation process using smart technologies to guide pre-tertiary students choose and follow the best professional career generated automatically by the IoT-school guidance system.
\end{abstract}

Keywords Internet of Things $\cdot$ Smart School Guidance $\cdot$ Career Path

\section{Introduction}

Modern technology is one of the elements that severely affects our daily life and provides tremendous solutions for humanity. Currently, information and communication technology (ICT) has the potential to change our world. It also represents a paradigmatic shift that may touch many other areas. The Internet of

Hicham EL MRABET

hi.elmrabet@gmail.com

Abdelaziz AIT MOUSSA

a_aitmoussa@yahoo.fr

1 Department of Computer Sciences, Faculty of Sciences, Mohammed I University, Oujda, Morocco 
Things (IoT) is one of these innovative technologies which was first invented in 1999. In the IoT, devices and things are equipped with sensors and wireless connections (WSN, RFID, NFC, Zigbee, BLE, WiFi) to collect, send and store data (Shah \& Yaqoob, 2016). The IoT permeates all areas of our daily life such as industry, energy, health, social life. Currently there is an increasing interest in internet of things and its role in educational systems (Kassab et al., 2019) which can facilitate education life and contribute to the effectiveness of educational practices (Uskov et al., 2016; Jeong et al., 2016; Songsom et al., 2019). The integration of the Internet of Things in education aims at building a smart environment through smart classrooms (Gligoric et al., 2012; El Mrabet et al., 2017), smart campuses, and smart school management systems (Vihervaara \& Alapaholuoma, 2017). The significance of the IoT was brought into light with the outbreak of covid-19 epidemic. The later resulted in the suspension of face to face schooling and imposed the distance learning mode which highly depends the internet in both teaching and counseling or mentoring.

The study of school guidance and the conscious choice of career (Mimis et al., 2018), is considered as one of the pillars of success in the educational course, since poor scholar guidance is always associated with failure at school. The reasons for this academic failure are numerous. They include the lack of a holistic view of the needs of the education system, the limited use of ICT and smart technologies, a weak and inconsistent guidance system and also the lack of a computerized system for guidance that meets the expectations of learners.

The purpose of smart guidance is to gradually replace the traditional school guidance, accompany students to make a conscious career choice and provide appropriate career opportunities for students. Moreover, it helps reduce dropouts in the first cycle of higher education and provide suggestions about the vocational career.

This paper is an attempt to provide a smart school guidance system based on IoT technology with versatile tools to help student in making the right choice about their vocational career. This system includes the automatic interaction between an IoTSchool guidance system at anytime, anywhere and on any device.

This research article is organized as follows: The second section presents a background of different approaches used for smart education and smart management system and summarizes the related work in smart guidance system. Third section presents the compiled research questions and the research methodology. The fourth section discusses and illustrates the experiments that have been conducted to evaluate the proposed solution and their interpretations. At the end, we will give some suggestions for future research.

\section{Background and related work}

Today, we can clearly see the growing importance of information and communication technologies (ICT) that are beginning to occupy an increasing space in our society. This digital revolution will have a major impact in radically changing the prospects for education and professions in the coming decades. Within this process, education will have to cope with these digital transformations. 
Smart school is a concept of developing online learning services applied to schools as an interaction between administrative staff, teachers, and students. Smart School aims to create a smart learning environment that is not limited in distance nor time through the use of information technology (Taleb \& Hassanzadeh, 2015). Smart school design, tends to transform classroom management and learning activities from traditional presential learning model into online modern learning. Online learning activities are carried out by students. That is, school materials, assignments, tests, exams, grades, discussions, and school counseling are shared and performed online.

\subsection{School orientation survey}

School orientation is announced as an integral part of the education process, as a support tool of students to facilitate educational and professional choices, and to reorient them whenever necessary, from high school to higher education. The expansion of educational applications in school guidance is shaped in accordance with the countries' educational objectives, pedagogical approaches, and by their political, social or economic objectives. Report ( $\mathrm{N}^{\circ}$ 5/2019) published on June 2019, the Superior Council of Education, Training and Scientific Research of Morocco which deals with dropping out of school in the first year of higher education, recorded a continuous decline in the graduation rate in 3-4 years, from 2007-2008 to reach its lowest level in 2012-2013 (19.1\%). As for redoubling students, this rate rose continuously to reach (47\%) in 2016-2017. More than $1 / 4$ of students drop out after one year of schooling (SCETSR, 2019). Part of the dropout rate is due to the lack of efficacy in the orientation systems for students.

The reasons for this poor performance are numerous, including the weak level of education for students, the absence of a work methodology and the limited use of smart technology, and the weakness of keeping pace with students at the level of guidance and building their academic and vocational project. Hence, it's high time the entire higher education system and secondary school, adopts intelligent devices to help students orient themselves or to reorient themselves during their academic journey and to help them build their professional projects.

Many students have not been oriented during their lifetime or poorly oriented, so these young learners find themselves in paths that do not correspond to the university or the profession desired profiles. These learners gradually move away from the appropriate path of their potential and take paths which do not match with their aspirations and they, consequently, face a number of obstacles, friction and failures during the school career as shown in Fig. 1.

We spend a lot of money, time, and research in all areas, but in the school guidance of our children and their future we find poor solutions. This survey has shown that there is no existing smart guidance system providing an interoperable tool in Morocco that cover the main pillars of school counseling from secondary school to higher education. On the other hand, a survey carried out in 2019 by our team to assess the effect level of school guidance, 398 professionals (Teachers and pedagogical counselors) were interviewed (El Mrabet et al. 2019). The quiz consists of 


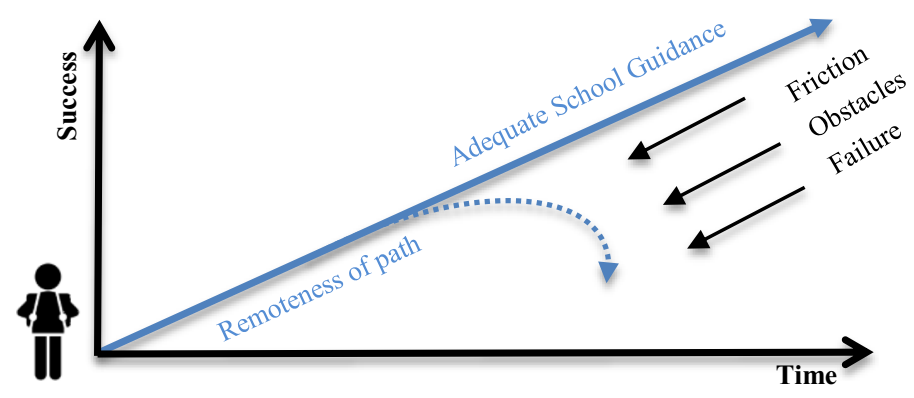

Fig. 1 Poorly oriented students

50 questions that cover the study of school guidance interest in Moroccan schools. All analyzes of the survey data reveals important results that greatly helped us in developing smart educational guidance and we found that guidance should take into consideration many factors: family impact, financial condition, prejudiced beliefs, educational institution impact, and community impact.

\subsection{The different school guidance systems}

The review and study of the existing related work in career guidance systems was examined to get a global idea on the different technologies used in order to approach the subject from all sides. Among the reasons which entails finding urgent solutions to guidance related problems is the lack of guidance counselors in some schools. This has led many students to make wrong career choices. Analysis of existing systems (John et al., 2016; Myla et al., 2019; Habsy et al., 2019; Winston et al., 2008) shows that its main objective is basically to help students in developing the individual growth about the professional career. Belskaya et al. (2016) illustrate the concept of "University Smart Guidance Counseling"; this seeks to create a favorable approach and a flexible system for successful adaptation of first-year by contributing to personality development of students. Also Abisoye et al. (2015) develop a "Web-Based Career Guidance Information System" which helps high school students in Nigeria to choose the best career path based on the test results; the system limitation is that it only uses one criterion, which may not give high data results. As well Balogun and Thompson (2009) develop a "Decision Support System (DSS) for Guidance and Counseling", the system consists of a database with student profile, study of test questions and answers used in assessments. The system enables the determination of the intelligence strength that was used in conjunction with the advice of the counselor, the advice of friends, and the interests of their parents to recommend an appropriate career path. The limitation of the system is that students cannot decide independently on the career choice but with other stakeholders who were part of the recommendation. Also Ankit et al. (2014) and Ihya et al. (2020) proposes a decision support system for determining right education career choice based on machine learning technique to get a decision support capability that includes user interface, knowledge base, and inference engine. 
After analyzing the aforementioned research, it was found that the limitations of most systems are reflected in the lack of motivation, lack of interactivity, indecision, and lack of information about the vocational world and also the lack to make a conscious decision on the part of students.

\section{Methods and theoretical framework}

The purpose of this research was to investigate the possibility of applying a smart guidance system in secondary school based on cognitive tendencies and personal choices and the improvement of school counseling experience by delivering suggestions that are suitable for learners in order to have a fulfilling orientation responds to the attitudes of students.

Our guidance system uses interactive activities during learning process and outside the school, such as group discussions, company visits, expert conferences, meetings with representatives of the private and public sectors. The functioning and success of our guidance system depends on the work of many elements:

- Pedagogical counselors

- Vocational sector

- Parents

- Students

- Smart technologies

- Teachers

In the context of our study, it is very interesting to consider the elements mentioned above as essential elements of our system which proposes an action plan to master the knowledge of the students. The action plan that will be presented by our system is to coordinate with pedagogical counselors, teachers and vocational sector at the beginning of each school season in order to accompany the rhythm of students using the system, which will propose academic areas adapted to the aspirations of the student according to the type of his personality and does not impose an obligation of choice.

To build smart school guidance for the recommendation and suggestion framework that predicts students' potential, and to provide support for school guidance, we propose IoT-School Guidance that focuses on the accuracy of self-knowledge and vocational path information needed to make a career decision and to help students to engage effectively in the world of work. The framework is designed for secondary school students in Morocco. Generally, all schools provide multidisciplinary programs and educational pathways to develop educational skills that allow the student to access the prestigious educational and vocational career. The Moroccan secondary schools are organized in five main areas and each area is divided into several sub-areas as shown in the Fig. 2. 

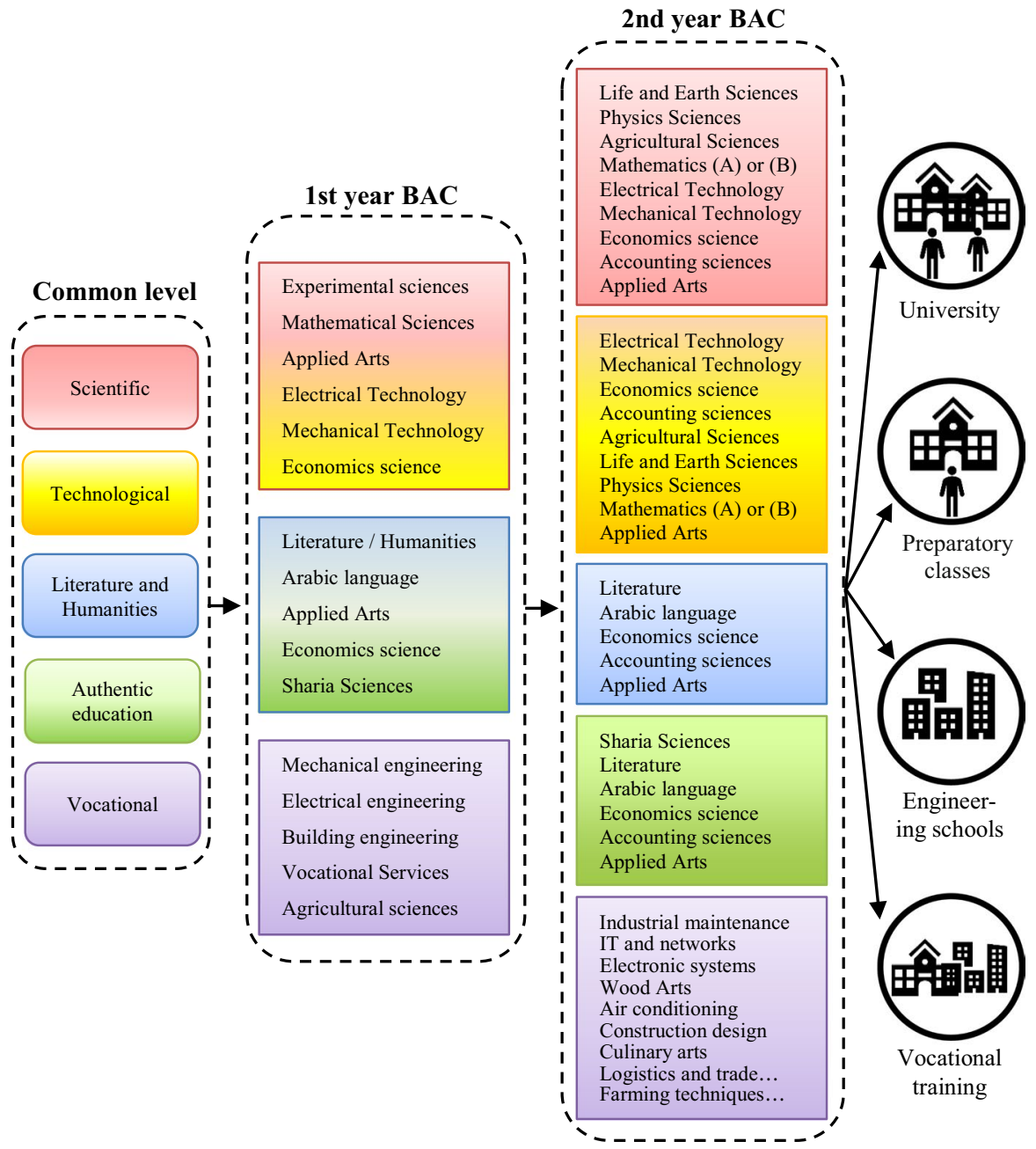

Fig. 2 The main educational paths

The colors in Fig. 2 represent the possible academic pathways for each stream. In other words, these colors show the pathways offered by the educational system in Morocco during three years of high school study.

\subsection{Theoretical framework}

\subsubsection{ETC-guidance approach}

Students need all aspects of the career process such as: understanding their interests and abilities, obtaining detailed information about the career path, exploring professions and other types of a specific job prospects. Basically, the research approach is 
based on ETC guidance methodology. The ETC-Guidance help students to identify their skills, their vocational opportunities and ability by analyzing their hobbies, background and testing their Intelligence. The cumulative result of ETC-Guidance helps in determining the list of majors that will be appropriate for the career path. The research methodology of ETC approach includes three pillars as shown in Fig. 3.

- The first component is 'Exploration': This phase explore the student's personal abilities and energies, discover the career paths and obtaining knowledge about the world of work that suit them and match their individual aspirations, and give the opportunity to see up close the available career paths.

- The second component 'Tendencies': The student's appropriate specialization cannot be determined without a thorough knowledge of his various mental abilities and skills. For it we compare what suits the student's passion and scientific trends with his professional and study skills.

- The third component is 'Choices': It is the final phase that paves the way for the appropriate choice for the learner. We compare what suits the passion and scientific tendencies of the student with his professional and cognitive skills in order to propose / recommend the suitable path, and to present other careers in the same sector.

\subsubsection{Smart school guidance}

The smart school guidance System developed in this paper was modeled basically on ETC approach and partially on the framework of John Holland (1997). Holland's theory suggests that people can be classified into several models (environments) and that the interaction between personality traits and similar environmental models leads to professional and psychological stability. Holland proposed six personality types:

- Realistic: This pattern is characterized by works that require physical exertion, skill, strength and consistency. One of the features of this style is that its owner is frank, consistent and practical and loves to deal with machines and tools.

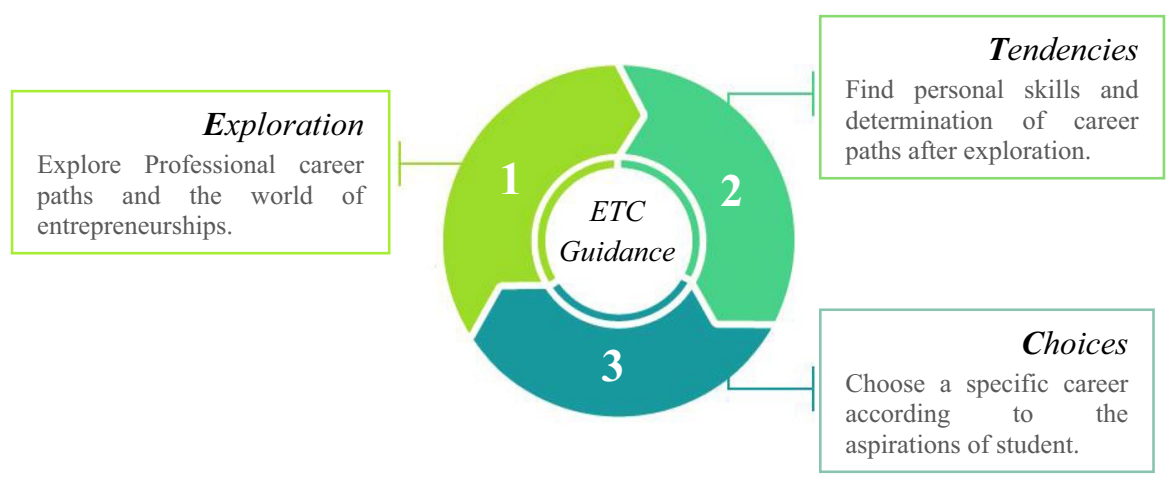

Fig. 3 ETC School guidance approach 
- Investigative: This pattern is characterized by being preferred to work through theories, thinking, organization and understanding. It also includes: the curiosity, analysis, independence, rationality, experimentation and research supervision.

- Artistic: This style is characterized by the fact that it favors creative, non-formal, and original works that stimulate the ability to be creative and innovative. Also, it features: imagination, impractical, disorganized, has an intuition, innovative, based on feelings and imagination.

- Social: The owner of this style prefers works that are of a charitable and social nature; contribute to helping others, or developing them for the better. Among its characteristics are: compassionate, helpful, kind, considerate, patient, caring for people and loves the work that is in a team.

- Enterprising: The owner of this style prefers competitive environments, leadership, and influence on others and is characterized by adventure. Among its characteristics are: ambitious, dominant, energetic, self-confident, enterprising, enthusiastic, optimistic. This type is dominant, persuasive, and motivating to others.

- Conventional: He prefers works that require accuracy, is subject to regulatory laws, respects hierarchy, and loves business that is ambiguous and vague. His features include: He loves conformity and is efficient and effective, practical and inflexible, with a clear conscience and a sense of responsibility.

We propounded an ETC approach of career guidance to organize the data about the different scholar paths identified above and the different work environments to suggest how students can make a career choices and to explain how job satisfaction subsist. Moreover, all bridges related to a specific field of work were identified and an overview of activities related to work samples and occupations was presented and thus linked to the academic course as shown in Table 1.

\section{4 loT-school guidance architecture}

IoT-School guidance focuses on the accuracy of self-knowledge and vocational path information needed to make a career decision and to help students to engage effectively in the world of work. Once the student is near an administration, factory, company, etc., can receive information about occupation directly on a smartphone, and make an appointment to visit the profession's headquarters to see its branches, offices, and horizons. A mobile application is required for the normal process of our system, but the constraints related to the environment of the city does not permit to perform such test with the application. In the preliminary steps we tried to use smartphones equipped with a RFID Tag and develop a prototype to detect and collect information. Afterwards, the system sends a questionnaire on the profession and collects information about the aspirations of the students. our system generates questions already stored in the database. In the first phase, the system generates randomly a set of questions from different 


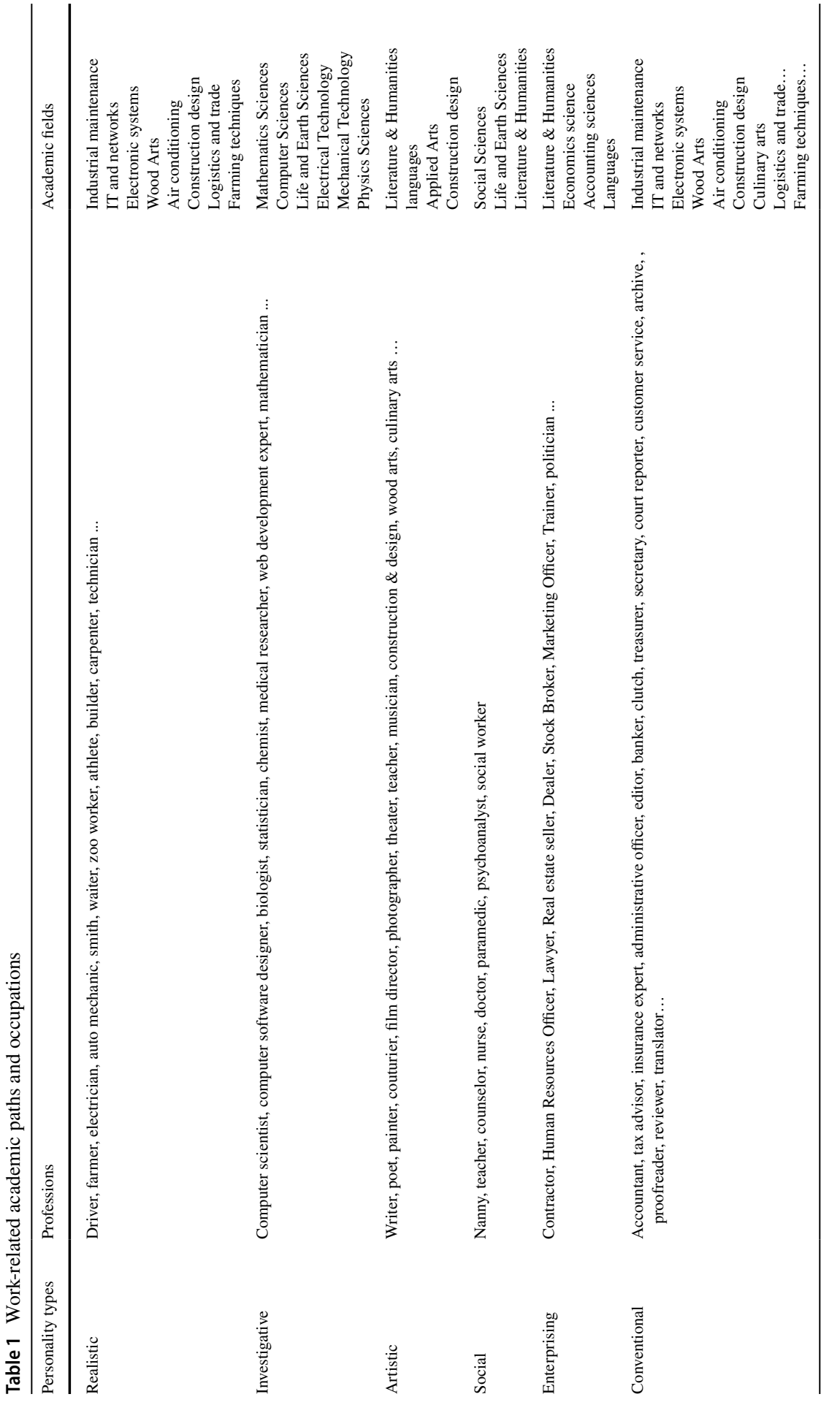


fields and different professions as shown in Table 2 in order to rank the appropriate sector of the learner. In the second phase, the system generates specific questions on the chosen sector in order to have more details on the professional career. Data will also be intensively collected from the psychological and personality measurement test to provide a report on the guidance of students. After collecting information about all occupational sectors explored by the student the system analyze the report and compare it with the personality type and student's academic record to suggest a career path at the end of the academic year. The architecture mainly includes the following elements:

Physical elements:

- RFID tags

- UHF Readers

- Arduino board

- Servers of management and notification

Software elements:

- JAVA JEE programming language

- SPRING Framework

- TOMCAT web server

- HSQLDB database

As shown in Fig. 4, the IoT-School guidance system uses RFID readers (Ultra High Frequency) that cover a 50m area, and a passive RFID tags attached to the student's card, smartphone. Firstly, the RFID reader starts the investigation of the area to detect a vocational labor and thereafter the information collected by the RFID reader will be transmitted via ARDUINO board to the administration server, to analyze the learner's file. Subsequently, the system sends the information about the profession and the company horizon. Secondly the system informs the educational counselor to support the student during the accompaniment phase and to help him to get more information about the profession and all bridges related to the vocational labor. On the other hand, the system generates questionnaires and tests as shown in Table 2 based on the subject of the profession concerned to accumulate and consolidate all the data and test results for educational guidance store the answers in a database in order to compare them with personality type and student advisory profile.

The first step consist of collecting "yes" marks for all the suggestions and arranging them according to the dominant personality in order to know the professional tendencies and start the exploration process. In general, we can say that the personality that gets the most "yes" marks is the field closest to the student's interest.

The second step focuses on the personality selected in the questionnaire and send another questionnaire to obtain more choices and information on this personality and his vocational career. Accordingly, and based on the tendencies, cognitive qualifications, and physical abilities, a specific career path is determined for the student. 
Table 2 Example of questionnaire

\begin{tabular}{|c|c|c|c|}
\hline Personality & Questions & Yes & No \\
\hline Realistic & $\begin{array}{l}\text { - I like taking care of animals } \\
\text { - I like planting and caring for plants } \\
\text { - I can work in difficult weather conditions } \\
\text { - I hope to drive some heavy machinery } \\
\text { - I like working with materials like wood and iron... } \\
\text { - I love doing kitchen chores } \\
\text { - I like to own a small seedling nursery } \\
\text { - I like using screwdrivers and screws } \\
\text { - I like to take things apart and assemble them } \\
\text { - ... }\end{array}$ & & \\
\hline Investigative & $\begin{array}{l}\text { - I am interested in modern technology } \\
\text { - I am interested in studying physics and chemistry } \\
\text { - I pay a lot of attention to agricultural products } \\
\text { - I am interested in studying life sciences and earth } \\
\text { - I enjoy working with computers } \\
\text { - I like the engines } \\
\text { - I am interested in renewable energies } \\
\text { - ... }\end{array}$ & & \\
\hline Artistic & $\begin{array}{l}\text { - I prefer to work in nature } \\
\text { - I am interested in artworks } \\
\text { - I am interested in the traditional industry } \\
\text { - I like to collect antiques } \\
\text { - I am interested in reading and writing } \\
\text { - I am interested in musical instruments } \\
\text { - . . }\end{array}$ & & \\
\hline Social & $\begin{array}{l}\text { - I like organizing trips } \\
\text { - I like to communicate with others } \\
\text { - I like the preservation of the environment } \\
\text { - I like helping others } \\
\text { - I like managing and organizing group activities } \\
\text { - I like to apply critical thinking skills in problem solving } \\
\text { - I like providing assistance to improve the well-being of peoples } \\
\text { - ... }\end{array}$ & & \\
\hline Enterprising & $\begin{array}{l}\text { - I like doing business } \\
\text { - I have the spirit of leadership } \\
\text { - I enjoy watching construction and architecture projects } \\
\text { - I like taking initiatives. } \\
\text { - I like dare, despite the risks and fears. } \\
\text { - I have the spirit of responsibility and commitment } \\
\text { - ... }\end{array}$ & & \\
\hline Conventional & $\begin{array}{l}\text { - I like arranging files } \\
\text { - I like the office environment } \\
\text { - I am interested in the economic field } \\
\text { - I like well-structured environments } \\
\text { - I like stable trades } \\
\text { - I appreciate the management activities } \\
\text { - I trust the authority and the law } \\
\text { - ... }\end{array}$ & & \\
\hline
\end{tabular}


The half-yearly results of the assessment and the score obtained from the tests have been stored for use in career choice. Finally, our system uses different wellknown classifiers for validating the output of decision making for career choice and to obtain recommendation of vocational paths and proposals are made for students regarding the choice of a school path and the choice of educational institution. Figure 5 shows the algorithm scheme for determining a conscious career choice.

The system is designed with Event-Driven Architecture paradigm which enables promoting, detection and consumption of events and ensure the concurrent access and parallel reaction events (notifications). Normally each student device is identified uniquely and as well the system is handling multiple users in parallel (Concurrency is Already Supported) the program will manage all notifications.

The student can benefit from the help of the system during the learner's school journey in the form of extracurricular activities. The repeated detection of the student's device in different locations is part of the data ingestion process, from which the system will use the data analysis model to rank student trends.

(3) Choice phase

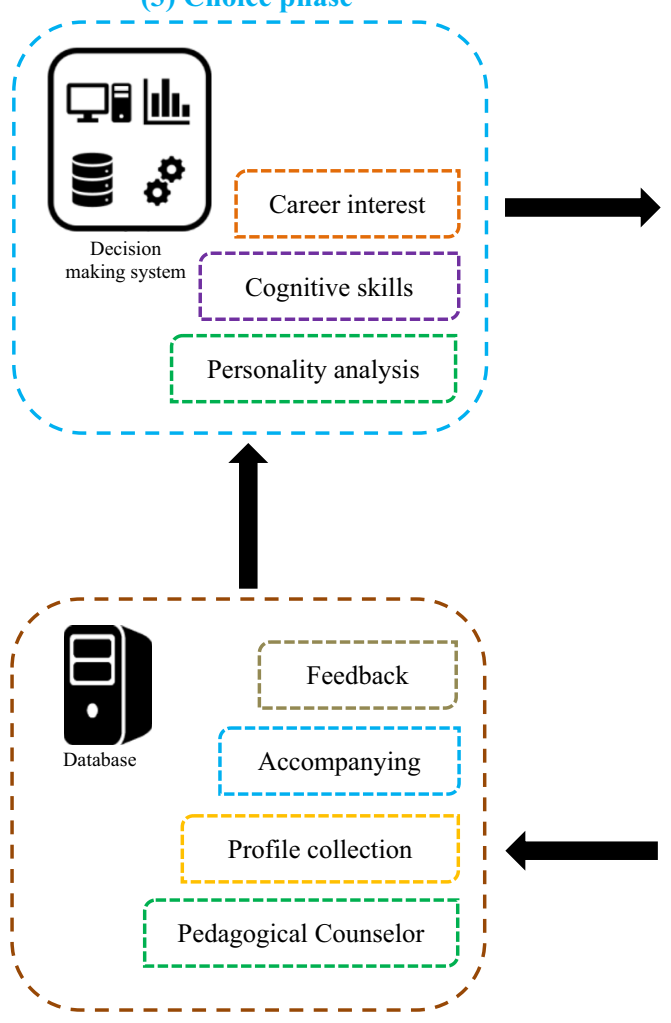

(2) Tendencies phase
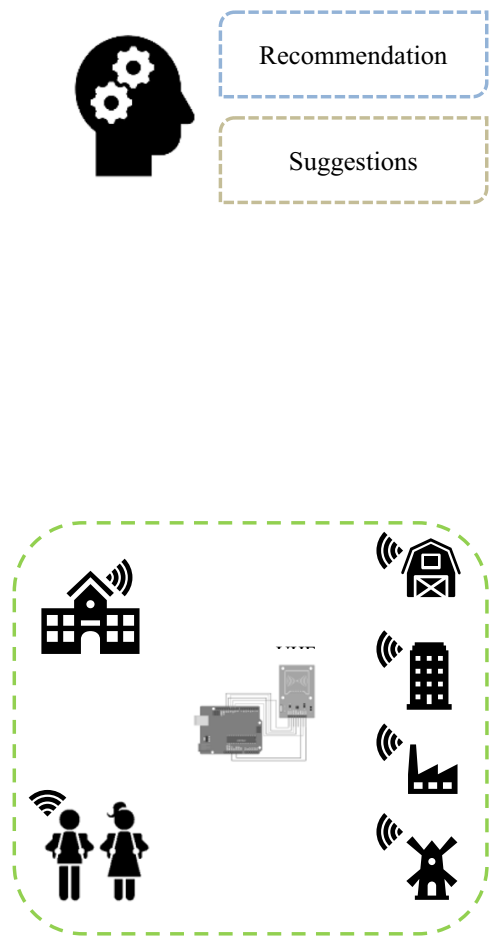

(1) Exploration phase

Fig. 4 The process of choosing a career 


\subsection{Decision methodologies}

In order to foster development of school guidance in education and create a favorable environment for successful adaptation of students some mathematical model of the data analysis process is proposed to determine student's educational inclinations and professional abilities.

A test of (I.Q), which tests intelligent quotient designed to aggregate a cognitive skills and to assess the ability of an individual to deal with certain problems, such as reasoning, planning, thinking, deducing.

$$
I=\frac{\text { Mental Age } \times 100}{\text { Chronological Age }}
$$

A student's personality can often converge on two personality types. For the two possible personality type Combination, the number of possible combinations from six basic personality types $\left(\mathrm{P}_{\mathrm{t} 1}=\right.$ Realistic, $\mathrm{P}_{\mathrm{t} 2}=$ Investigative, $\mathrm{P}_{\mathrm{t} 3}=$ Artistic, $\mathrm{P}_{\mathrm{t} 4}=$ Social, $\mathrm{P}_{\mathrm{t} 5}=$ Enterprising, $\mathrm{P}_{\mathrm{t} 6}=$ Conventional) was obtained by using combination formula:

$$
C_{n}^{k}=\frac{n !}{k !(n-k) !} \text { Where } n=6 \text { and } k=2
$$

A student Si finishes secondary school at age $\mathrm{i}$ and wishes to obtain a good guidance path. Therefore a student guidance data analysis process was proposed:

$$
S i=(E, R, C, D)
$$

Where E represent the occupations discovered by a student during the exploration phase from the set of $\mathrm{n}$ professions.

$$
E=\sum_{p=1}^{n} \operatorname{Disc}_{p}
$$

And $\mathrm{R}$ is results of tests divided into classes $\mathrm{R}=\left\{R_{\text {skill }}, R_{\text {interes }}, R_{I . Q}\right\}$ where $R_{\text {skill }}$ is cognitive skills, and ability result, $R_{\text {interest }}$ is a career Interest Result, $R_{I . Q}$ is intelligence quotient result. $\mathrm{C}$ represents two possible personality type Combination from six personality types: $P=\left\{P_{t 1}, P_{t 2}, P_{t 3}, P_{t 4}, P_{t 5}, P_{t 6}\right\}$. The decision-making D takes the form of:

$$
D=(E \cup R \cup C)
$$

\section{Result and discusion}

The orientation assistance system (IoT-School Guidance) used in this research integrates mobile devices with internet of things to get a vocational career choice. With the convenience offered by internet of things, students were able to do a conscious choice via the use of IoT-School Guidance anytime and anywhere. As expected, results of the half-year showed that there was a difference between the 


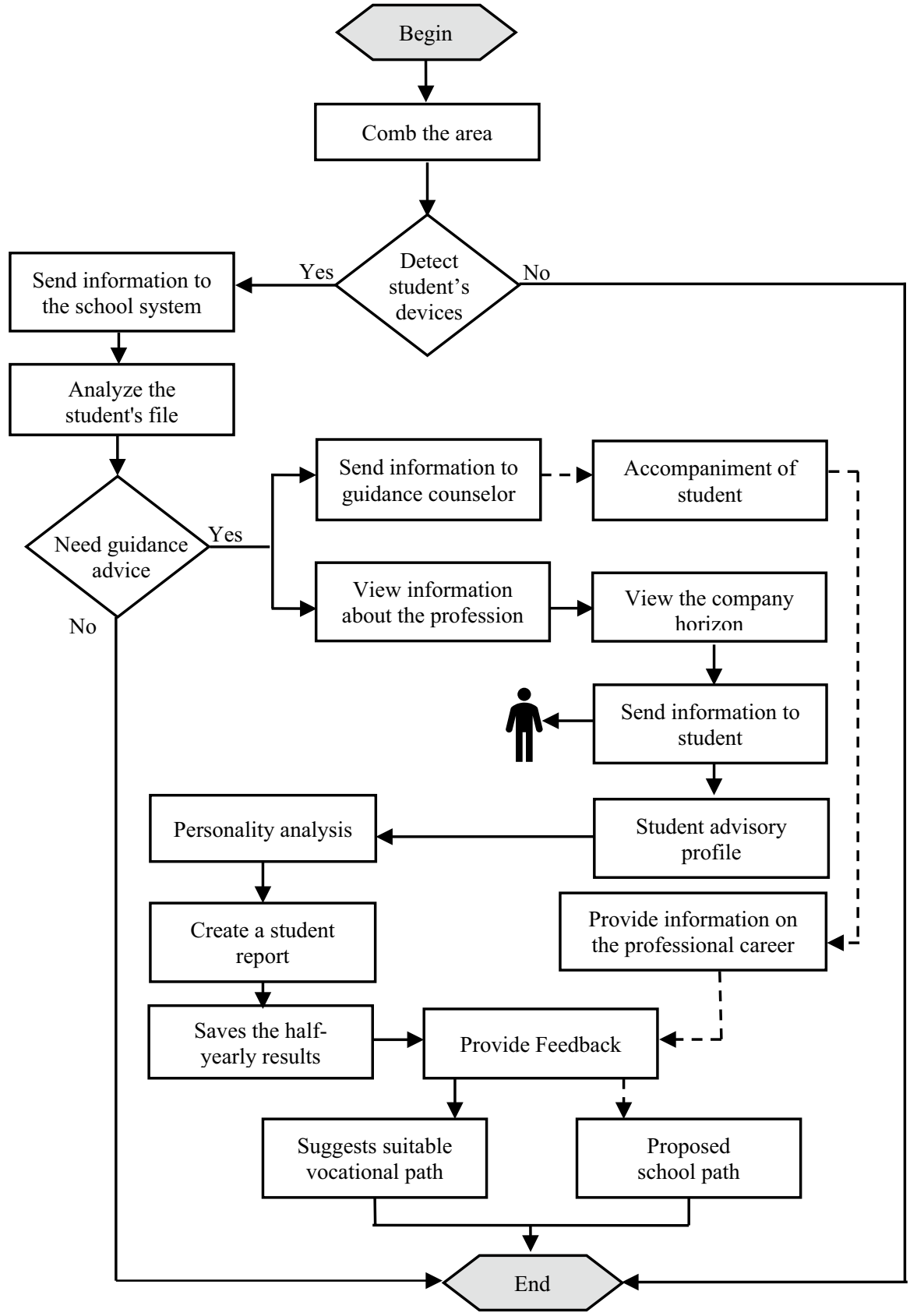

Fig. 5 Algorithm for determining a career choice 
experimental group and control group. The results and discussions below explain how the two groups differ on these aspects after having used the IoT-school orientation vocational career choice. In order to evaluate the performance of the developed IoT-school guidance system, the system was implemented with test for students. The participants in this experiment targeted students in the first year of high school. Therefore, the experimental group consisted of 33 students, while the control group was made up of 30 students from another class. The only difference was that the experimental group used IoT-school guidance, while the control group only had personality tests and psychometric tests. The experiment lasted for one full semester. Before the experiment, the students of the two groups filled out a questionnaire on their academic motivation and their professional tendencies. Our system will provide data analytics module (subsystems) which will display statistical metrics based on these results. So, the questionnaire includes general questions about the learner's preliminary tendencies, professional areas and extracurricular activities. The role of this questionnaire is to compare the results before the experiment and the results predicted from our system.

Table 3 shows the results of ANOVA test of the student guidance. We have already produced some interesting preliminary results. For example, we have observed conditions where it is always more advantageous to explore several professions before choosing a school path. We can see that there is a significant difference in the career path results between the control group and the experimental group.

However, a vocational self-awareness of the experiment group increased significantly $(F=4,516$, Sig $<0.05)$, whereas the self-awareness of the control group did not $(F=0,079, \operatorname{Sig}>0.05)$. This indicates that there is a significant difference in the self-awareness before and after their exposure to the IoT-School guidance.

The results in Table 4 show that a student's motivation in IoT-School guidance system is better than the traditional counseling method. Students were more willing to use IoT-school guidelines and had an interaction relationship with counseling professionals. Therefore, the hypothesis (that smart school guidance for vocational self-awareness choice is more effective) is accepted in this experiment.

\section{Conclusion}

This paper introduces the concept of smart school on the basis of integrating smart management system and career guidance system so that awareness of student orientation in the smart school can be very helpful in providing an informed and timely career choice. The primary goal of the smart guidance system is to provide a counseling process that lies in distributing students between the different paths and career options available. 
Table 3 Results for vocational self-awareness.

\begin{tabular}{lllllll}
\hline Group & $\mathrm{N}$ & Test & Mean & SD & F & Sig \\
\hline Experimental & 33 & Pretest & 51,272 & 16,611 & 4,516 & 0,037 \\
(IoT Counseling test) & & Posttest & 65,696 & 12,541 & & \\
Control & 30 & Pretest & 52,466 & 16,894 & 0,079 & 0,778 \\
(Traditional counseling test) & & Posttest & 58,100 & 15,775 & & \\
\hline
\end{tabular}

The one that we have developed in this paper is very different and can combine the current approaches to career counseling which articulates a classic approach by the use of psychometric tests with a more modern approach using the ICT seeking to identify trends of each learner. In this system, students can easily interact with the professional world in classroom or outside the classroom on the basis of high-end devices which aim to collect the necessary information on different professional fields and also the information about the profile of the student (trends, cognitive abilities, interests, and self-esteem) and then redirect students to the appropriate academic path. Our approach has a potential impact in guidance system and syntheses of these methods possibly provide better designs. Specifically, students utilize devices such as tablets, smartphones, and the students' card, meanwhile, we provide student with useful information about the labor sector. The students' feedbacks prove that the system is appropriate for effectively increasing cognitive skills of students, and possibly reducing the gap between schools and vocational sector in a specific area. In fact, it only works in an environment that has smart systems in most sectors, such as smart cities. As cities get smarter, this smart counseling approach will become more usable and more responsive. We are aware of the limitations of our approach that only works in smart cities and smart environments equipped by smart things, but we believe we have largely achieved the objective of our desired research.

Future work aims to develop a smart school guidance based on profiling system that allows gathering information about students' tendencies, according the aspirations of students and their choices of studies in a smart campus. Further work can be done to improve and refine the mentoring system, especially in the educational design aspect.

Table 4 ANOVA result for guidance motivation.

\begin{tabular}{llllrll}
\hline Test & Group & N & Mean & SD & F & Sig \\
\hline Pretest & Experimental & 33 & 42,757 & 12,612 & 0,024 & 0,876 \\
& Control & 30 & 43,300 & 15,019 & & \\
Posttest & Experimental & 33 & 62,060 & 9,649 & 5,802 & 0,019 \\
& Control & 30 & 55,100 & 13,163 & & \\
\hline
\end{tabular}




\section{References}

Ankit, M., Ashutosh, S., Sunil, K.S., Pardeep, K., \& Durg, S.C. (2014). Decision support system for determining: right education career choice. International Conference on Communication and Computing (ICC-2014), pp. 8-17. Bangalore, India.

Abisoye, O. A., Alabi, I., Ganiyu, S. O., Abisoye, B. O., \& Omokore, J. (2015). A Web-Based Career Guidance Information System for Pre-Tertiary Institutions Students in Nigeria. Journal of Scientific Research in Science, Engineering and Technology, 1(3), 229-240

Belskaya, E., Moldovanova, E., Rozhkova, S., Tsvetkova, O., \& Chervach, M. (2016). University Smart Guidance Counselling. In: Uskov V., Howlett R., Jain L. (eds) Smart Education and e-Learning, pp. 39-49. Smart Innovation, Systems and Technologies. Springer, Cham. https:// doi.org/10.1007/978-3-319-39690-3_4

Balogun, V. F., \& Thompson, A. F. (2009). Career Master: A Decision Support System (DSS) for Guidance and Counseling in Nigeria. Pacific Journal of Science and Technology., 10(2), 337-354

El Mrabet, H., \& Moussa, A. A. (2019). Smart School Guidance and Vocational Guidance System Through the Internet of Things. Proceedings of the 2nd International Conference on Networking, Information Systems \& Security - NISS19. https://doi.org/10.1145/3320326.3320404

EL Mrabet, H., \& Ait Moussa, A. (2017). Smart Classroom Environment Via IoT in Basic and Secondary Education. Transactions on Machine Learning and Artificial Intelligence, 5(4). https:// doi.org/10.14738/tmlai.54.3191

Gligoric, N., Uzelac, A., \& Krco, S. (2012). Smart classroom: real-time feedback on lecture quality. Proceedings of 2012 IEEE International Conference on Pervasive Computing and Communications Workshops (PERCOM Workshops), pp. 391-394. https://doi.org/10.1109/PerComW. 2012.6197517

Habsy, B., Hidayah, N., Lasan, B. B., Muslihati, M., \& Fudholi, A. (2019). The Development Model of Semar Counselling to Improve the Self-Esteem of Vocational Students with Psychological Distress. International Journal of Emerging Technologies in Learning (iJET), 14(10), 132-149. https://doi.org/10.3991/ijet.v14i10.10221

Holland, J. L. (1997). Making vocational choices: A theory of vocational personalities and work environments (3rd ed.). Psychological Assessment Resources

Ihya, R., Aitdaoud, M., Namir, A., Guerss, F.Z., \& Haddani, H. (2020). Using Machine Learning Algorithms to Predict the E-orientation Systems Acceptancy. In: Ben Ahmed M., Boudhir A., Santos D., El Aroussi M., Karas İ. (eds) Innovations in Smart Cities Applications Edition 3, pp. 117-130. Lecture Notes in Intelligent Transportation and Infrastructure. Springer, Cham. https:// doi.org/10.1007/978-3-030-37629-1_10

Jeong, G.M., Truong, P.H., Lee, T.Y., Choi, J.W., \& Lee, M. (2016). Course design for internet of things using lab of things of microsoft research. IEEE Frontiers in Education Conference (FIE). pp. 1-6. https://doi.org/10.1109/FIE.2016.7757396

John, I. E., Udofia, N. A., Udoh, N. A., \& Anagbogu, M. A. (2016). Development of e-career guidance programme for secondary schools in Akwa IbomState. Educational Media International. https://doi.org/10.1080/09523987.2016.1254886.

Kassab, M., DeFranco, J., \& Laplante, P. (2019). A systematic literature review on Internet of things in education: Benefits and challenges. Journal of Computer Assisted Learning. pp 1-14. https:// doi.org/10.1111/jcal.12383

Mimis, M., El Hajji, M., Es-saady, Y., Oueld Guejdi, A., Douzi, H., \& Mammass, D. (2018). A framework for smart academic guidance using educational data mining. Education and Information Technologies, 24(2), 1379-1393. https://doi.org/10.1007/s10639-018-9838-8

Myla, S., Marella, S. T., Goud, A. S., Ahammad, S. H., Kumar, G., \& Inthiyaz, S. (2019). Design Decision Taking System For Student Career Selection For Accurate Academic System. Journal of Scientific \& Technology Research, 8(9), 2199-2206

Songsom, N., Nilsook, P., Wannapiroon, P., Fung, C. C., \& Wong, K. W. (2019). System architecture of a student relationship management system using Internet of Things to collect Digital Footprint of Higher Education Institutions. International Journal of Emerging Technologies in Learning, 14(23), 125-140. https://doi.org/10.3991/ijet.v14i23.11066

SCETSR. (2019). Report of Superior Council for Education, Training and Scientific Research of Morocco. https://www.csefrs.ma/wp-content/uploads/2019/07/enseignement-supe\%CC\%81rieurfr.pdf 
Shah, S., \& Yaqoob, I. (2016). A survey: Internet of Things (IOT) technologies, applications and challenges. Smart energy grid engineering (SEGE). pp 381-385. https://doi.org/10.1109/SEGE. 2016.7589556

Taleb, S., \& Hassanzadeh, F. (2015). Toward Smart School: A Comparison between Smart School \& Traditional School for Mathematics Learning. 5th ICEEPSY International Conference on Education \& Educational Psychology, Social \& Behavioral Sciences, (171), 90-95. https://doi.org/10. 1016/j.sbspro.2015.01.093

Uskov, V., Pandey, A., Bakken, J. P., \& Margapuri, V. S. (2016). "Smart engineering education: The ontology of Internet-of-Things applications", IEEE Global Engineering Education Conference, EDUCON, 10-13-April-2016, art. no. 7474596, pp. 476-481. https://doi.org/10.1109/EDUCON. 2016.7474596

Vihervaara, J., \& Alapaholuoma, T. (2017). Internet of Things: Opportunities for Vocational Education and Training - Presentation of the Pilot Project. In Proceedings of the 9th International Conference on Computer Supported Education, Volume 1, pages 476-480. https://doi.org/10.5220/0006353204 760480

Winston, O., \& Lawrence, M. (2008). Career Guidance Using Expert System Approach, in 4th annual international conference on computing and ICT research - ICCIR 08, Kampala, pp. 123-131

Publisher's Note Springer Nature remains neutral with regard to jurisdictional claims in published maps and institutional affiliations. 